\title{
Akwizycja planarna a SPECT/CT w detekcji węzłów wartowniczych w raku sutka*
}

\section{Comparison of planar and SPECT/CT imaging in the detection of sentinel lymph nodes in breast cancer}

\author{
Sylwia Jankowska ${ }^{\bowtie}$ \\ Pomorski Uniwersytet Medyczny w Szczecinie, Katedra i Zakład Patomorfologii, ul. Unii Lubelskiej 1, 71-242 Szczecin \\ $\triangle$ sylwia_jankowska@interia.eu
}

\begin{abstract}
Introduction: Sentinel lymph node biopsy is an increasingly popular method of breast cancer treatment. In order to determine the number and location of potentially positive nodes, it is necessary to perform sentinel node lymphoscintigraphy. The quality of the image depends on the use of the appropriate method of radionuclide imaging.

The aim of this study was to compare the sensitivity of SPECT, SPECT/CT and classical planar acquisitions in the detection of sentinel lymph nodes for sentinel node lymphoscintigraphy in breast cancer. In addition, we tried to verify the usefulness of the morphological image obtained by SPECT/CT to specify their location. Materials and methods: We studied 62 women (mean age $=58$ $\mathrm{SD}=10.28$ ) with histologically confirmed breast cancer (To-2NoMo). Planar, SPECT and SPECT/CT images were interpreted separately in terms of the number and location of sentinel lymph nodes and lymphatic drainage direction.

Results: Planar images detected 93 sentinel lymph nodes, while SPECT and SPECT/CT showed 114 nodes (about 22\% more).
\end{abstract}

In $15(24 \%)$ patients SPECT imaging detected more sentinel lymph nodes than planar. Planar imaging was negative for the identification of sentinel lymph nodes in $6(10 \%)$ patients. SPECT/CT images showed sentinel lymph nodes in all patients. The node to background ratio on the planar images was 11.6, on the SPECT 134.9, and on the SPECT/CT 147.5. The direction of lymphatic drainage and location of axillary lymph nodes were established only on SPECT/CT images.

Conclusions: The use of SPECT imaging for sentinel node lymphoscintigraphy in breast cancer increases the sensitivity of sentinel lymph nodes detection. The use of low-dose CT as attenuation correction for SPECT images improves their contrast without a significant effect on the number of detected sentinel lymph nodes. It also brings important anatomical information, which is difficult or even impossible to determine by planar and SPECT images.

Keywords: radionuclide imaging; sentinel lymph node biopsy; single-photon emission computed tomography; breast neoplasms.

\begin{abstract}
ABSTRAKT
Wstęp: Biopsja węzła wartowniczego jest coraz częściej wybieraną metodą leczenia raka sutka. W celu określenia liczby i lokalizacji potencjalnie zajętych węzłów niezbędne jest przeprowadzenie limfoscyntygrafii węzła wartowniczego. Jakość powstałych obrazów limfoscyntygraficznych zależy od doboru odpowiednio czułej metody obrazowania.

Celem pracy było porównanie czułości techniki tomografii emisyjnej pojedynczego fotonu (SPECT), techniki fuzyjnej łączącej SPECT z tomografią komputerową (SPECT/CT) i klasycznej akwizycji planarnej w detekcji węzłów wartowniczych w limfoscyntygrafii u chorych na raka sutka oraz ocena przydatności obrazu morfologicznego uzyskanego za pomocą SPECT/CT do ich lokalizacji.

Materiały i metody: Przebadano 62 kobiety (średni wiek - 58 lat, $\mathrm{SD}=10,28) \mathrm{z}$ potwierdzonym histopatologicznie rakiem sutka (To-2NoMo). U wszystkich pacjentek wykonano limfoscyntygrafię węzłów wartowniczych kolejno metodami: planarną, SPECT i SPECT/CT. Otrzymane obrazy porównano pod względem liczby węzłów wartowniczych, ich lokalizacji oraz kierunku spływu limfatycznego.
\end{abstract}

Wyniki: W badaniach planarnych uwidoczniono 93 węzły wartownicze. Z kolei za pomocą technik SPECT i SPECT/CT znaleziono ich 114 (o 22\% więcej). U 15 (24\%) pacjentek w obrazach SPECT zlokalizowano więcej węzłów wartowniczych niż w obrazach planarnych. U wszystkich kobiet w obrazach SPECT były widoczne węzły wartownicze, natomiast metodą planarną u 6 (10\%) chorych w ogóle ich nie wykryto. Średni stosunek zmiana/ tło w obrazach planarnych wyniósł 11,6, w obrazach SPECT - 134,9, a w obrazach SPECT/CT - 147,5. Kierunek spływu limfatycznego i lokalizację węzłów wartowniczych dołu pachowego określono jedynie w obrazach SPECT/CT.

Wnioski: Użycie techniki SPECT w limfoscyntygrafii węzła wartowniczego zwiększa czułość detekcji węzłów wartowniczych w raku sutka. Zastosowanie w metodzie SPECT niskodawkowej tomografii komputerowej poprawia kontrast obrazu, nie wpływając istotnie na liczbę uwidocznionych w limfoscyntygrafii węzłów wartowniczych. Wnosi natomiast istotną informację anatomiczną, niemożliwą do określenia w badaniu planarnym i SPECT. Słowa kluczowe: obrazowanie radioizotopowe; biopsja węzła wartowniczego; tomografia emisyjna pojedynczych fotonów; nowotwory sutka.

* Zwięzła wersja pracy magisterskiej obronionej na Wydziale Lekarsko-Biotechnologicznym i Medycyny Laboratoryjnej Pomorskiego Uniwersytetu Medycznego w Szczecinie. Promotor: dr n. med. Piotr Zorga. Oryginalny maszynopis obejmuje: 49 stron, 9 rycin, 7 tabel oraz 53 pozycje piśmiennictwa. 


\section{WSTEP}

Biopsja węzła wartowniczego stała się niemalże rutynowym postępowaniem medycznym w przypadku leczenia raka sutka. Jest to operacja oszczędzająca dół pachowy, stosowana w rakach inwazyjnych w I i II stopniu zaawansowania klinicznego. Poza stosunkowo niewielką ingerencją w ciało pacjenta, jej skuteczność jako metody leczniczej jest bardzo duża [1, 2, 3, 4, 5]. Kolejną zaletą stosowania biopsji węzła wartowniczego jest poprawa komfortu fizycznego i psychicznego chorego. Wyniki licznych badań dowodzą, że jakość życia osób po operacji oszczędzającej jest zdecydowanie lepsza niż po mastektomii radykalnej. U chorych odnotowuje się m.in. mniejszy ból pooperacyjny, szybszy powrót do zdrowia, skrócony czas hospitalizacji, lepszą sprawność ruchową kończyny górnej, mniejszy odsetek obrzęków limfatycznych oraz zdecydowanie lepsze samopoczucie [3, 4].

W celu określenia liczby i lokalizacji potencjalnie zajętych węzłów, niezbędne jest przeprowadzenie limfoscyntygrafii węzła wartowniczego. $\mathrm{W}$ badaniu tym wyznakowane radioznacznikiem węzły chłonne mogą być obrazowane trzema metodami: planarną, tomografii emisyjnej pojedynczego fotonu (single-photon emission computed tomography - SPECT) oraz fuzyjną, łączącą SPECT z tomografią komputerową (SPECT/CT). Technika planarna charakteryzuje się niską rozdzielczością i słabym kontrastem, przez co powstaje obraz o małej ostrości. Skutkuje to słabszą detekcją zajętych przez nowotwór węzłów chłonnych. Zastosowanie trójwymiarowej techniki SPECT pozwala uzyskiwać obrazy o wysokiej rozdzielczości i kontraście w poszczególnych warstwach badanego obiektu.

Według przeanalizowanego piśmiennictwa, najlepsze efekty daje technika fuzyjna SPECT/CT, która pozwala na bardzo dokładne dopasowanie współrzędnych otrzymanych w badaniu SPECT do obrazu anatomicznego uzyskanego za pomocą następującego zaraz po nim badania CT. Skutkuje to wyższą rozdzielczością i mocniejszym kontrastem otrzymanych obrazów $[5,6,7,8,9,10]$.

Celem pracy było porównanie czułości klasycznej akwizycji planarnej oraz technik SPECT i SPECT/CT w detekcji węzłów chłonnych wartowniczych oraz ocena przydatności obrazu morfologicznego uzyskanego za pomocą SPECT/CT do ich lokalizacji.

\section{MATERIAtY I METODY}

Grupę badaną stanowiły 62 kobiety w wieku 32-86 lat (średnia wieku 58 lat, $S D=10,28$ ) z potwierdzonym histopatologicznie rakiem złośliwym sutka (To-2NoMo) i wskazaniem klinicznym do przeprowadzenia biopsji węzła wartowniczego. Zabieg tumorektomii przeszło uprzednio 13\% kobiet. Chore $\mathrm{z}$ rakiem sutka lewego stanowiły $60 \%$ grupy badanej, resztę zaś pacjentki z rakiem sutka prawego.

Do badania zastosowano nonokoloid albuminowy (Nanocoll@, firmy GE Healthcare) znakowany izotopem technetu ( ${ }^{99 \mathrm{~m}} \mathrm{Tc}$ ) o aktywności 180-200 MBq. Przeprowadzono iniekcję śródskórną nad guzkiem, a w przypadku chorych po tumorektomii wokół blizny pooperacyjnej. Okres oczekiwania na akwizycje wynosił 2-5 godz.

Każdorazowo wykonano scyntygrafię planarną oraz bezpośrednio po niej SPECT/CT. Badania przeprowadzono z użyciem hybrydowego systemu Infinia Hawkaye 4 (firmy GE Healthcare) złożonego z dwugłowicowej gammakamery oraz niskodawkowego, spiralnego tomografu komputerowego wyposażonego w niskoenergetyczny kolimator o wysokiej rozdzielczości. Analizator energii został ustawiony na rejestrację fotonów o energii $140 \mathrm{keV}$, z zastosowaniem okna energetycznego $\pm 10 \%$.

W badaniach planarnych zastosowano matrycę $256 \times 256$ pikseli, z głębokością kodowania 8 bitów. Wykonywano akwizycje 10-minutowe w projekcjach A-P, przednio-skośnej i bocznej z przysłonięciem miejsca iniekcji ołowianą płytką. W badaniach SPECT zastosowano matrycę $128 \times 128$ pikseli, z głębokością kodowania 8 bitów. Wykonywano 64 projekcje, po $10 \mathrm{~s}$ każda, z pełnym obrotem analizatora wokół pacjenta. W badaniach SPECT/CT wykonywano dodatkowo spiralną, niskodawkową tomografię komputerową na matrycy $512 \times 512$ pikseli, z natężeniem prądu 2,5 mA oraz napięciem $140 \mathrm{kV}$. Po akwizycji każdy obraz został poddany wstępnej filtracji dedykowanej dla tkanek miękkich.

Obraz zrekonstruowano za pomocą oprogramowania Volumetrix for Hawkeye dla stacji przetwarzania danych Xeleris firmy GE Healthcare, metodą rekonstrukcji iteracyjnej OSEM, z mechanizmem korekcji pochłaniania o obraz CT oraz korekcją na rozpad ${ }^{99 \mathrm{~m}} \mathrm{Tc}$.
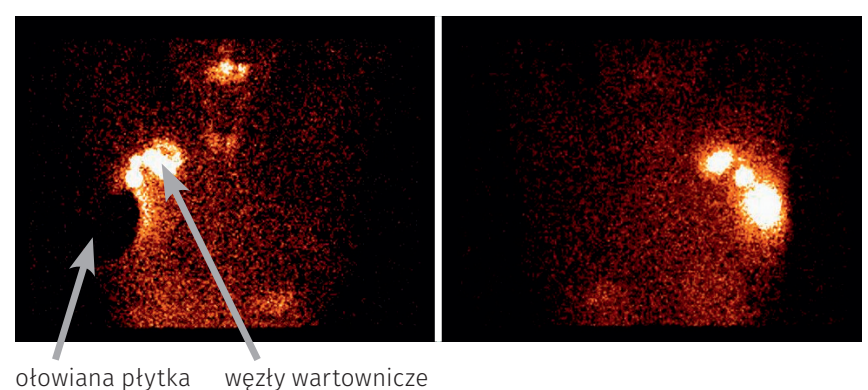

RYCINA 1. Przykład obrazu planarnego

Obrazy zostały ocenione pod względem liczby wyznakowanych węzłów wartowniczych, kontrastu oraz w przypadku obrazów SPECT/CT - kierunku spływu limfatycznego do jednej z trzech lokalizacji: dołu pachowego, okolicy obojczykowej lub śródpiersia. Lokalizację węzłów znajdujących się w dole pachowym odniesiono do znajdujących się w nim struktur anatomicznych: tkanki tłuszczowej, bocznej krawędzi mięśnia piersiowego, ściany klatki piersiowej lub dużych naczyń. Dodatkowo określono ich lokalizację w oparciu o podział dołu pachowego na piętra (I, II, III). Przykładowe obrazy planarne i SPECT/CT przedstawiono na rycinach 1 i 2.

\section{WYNIKI}

W badaniu planarnym łącznie uwidoczniono 93 węzły wartownicze. W badaniach SPECT i SPECT/CT znaleziono ich 114 (o 22\% więcej). U 15 (24\%) pacjentek w obrazach SPECT zlokalizowano więcej węzłów wartowniczych niż w obrazach planarnych. 


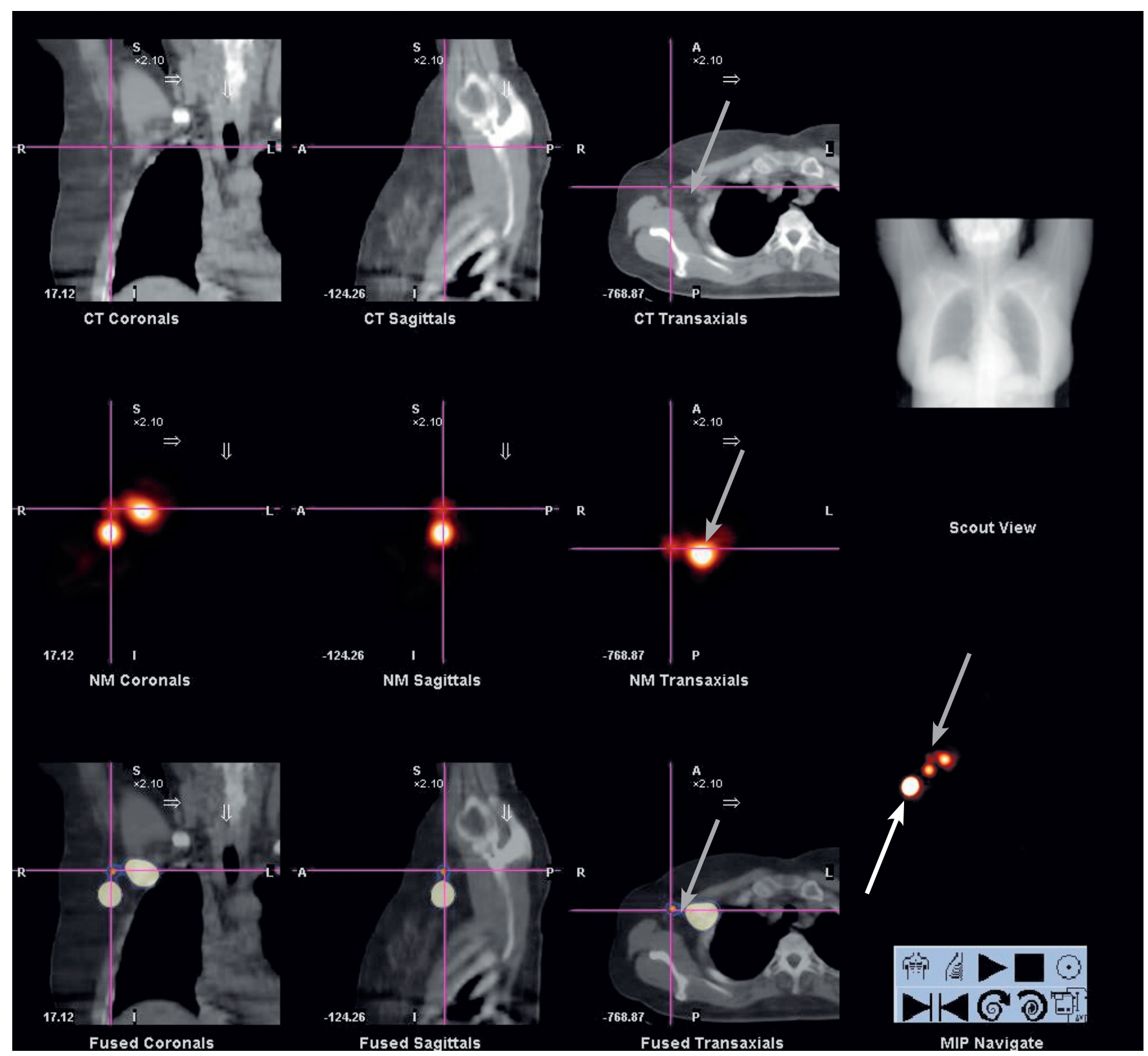

RYCINA 2. Przykład obrazu SPECT/CT (strzałki szare - węzły wartownicze, strzałka biała - miejsce iniekcji)

Z czego u 10 (67\%) z nich było to o 1 węzeł, u 4 (27\%) o 2 węzły, a u $1(6 \%)$ o 3 węzły więcej. W obrazach uzyskanych techniką SPECT węzły wartownicze były widoczne u wszystkich pacjentek. Z kolei w badaniu planarnym u 6 (10\%) chorych w ogóle ich nie wykryto, przy czym u 5 z nich węzeł wykryty za pomocą badania SPECT/CT był jedynym wyznakowanym. Średni stosunek zmiana/tło dla węzłów wartowniczych w badaniach planarnych wyniósł 11,6, z kolei w badaniach SPECT stosunek ten był niemal 12-krotnie wyższy $(134,9)$. Zastosowanie korekcji pochłaniania zmieniło wspomniany stosunek ze 134,9 na 147,5. Wyniki przedstawiono w tabeli 1.

W obrazach SPECT/CT u wszystkich pacjentek określono kierunek spływu limfatycznego i lokalizację węzłów wartowniczych pachowych w odniesieniu do struktur anatomicznych i pięter pachy. U 61 (99\%) pacjentek zobrazowano spływ limfatyczny w kierunku dołu pachowego, zaś u 1 (1\%) pacjentki do okolicy obojczykowej. Nie zaobserwowano spływu chłonki do śródpiersia i innych okolic. Natomiast spośród 112 węzłów znajdujących się w dole pachowym 55 (49\%) zlokalizowanych było w tkance tłuszczowej dołu pachowego, 31 (28\%) przy bocznej krawędzi mięśnia piersiowego, 17 (15\%) przy ścianie klatki piersiowej, zaś 9 (8\%) w sąsiedztwie dużych naczyń dołu

TABELA 1. Porównanie czułości metody planarnej i technik tomograficznych w detekcji węzłów wartowniczych

\begin{tabular}{lccc}
\multicolumn{1}{c}{ Parametr } & $\begin{array}{c}\text { Badanie } \\
\text { planarne }\end{array}$ & $\begin{array}{c}\text { Badanie } \\
\text { SPECT }\end{array}$ & $\begin{array}{c}\text { Badanie } \\
\text { SPECT/CT }\end{array}$ \\
\hline $\begin{array}{l}\text { Liczba widocznych węztów } \\
\text { wartowniczych }\end{array}$ & 93 & 114 & 114 \\
\hline $\begin{array}{l}\text { Liczba pacjentek z widocznymi } \\
\text { węztami wartowniczymi }\end{array}$ & 56 & 62 & 62 \\
\hline Średni stosunek zmiana/tło & 11,6 & 134,9 & 147,5 \\
\hline
\end{tabular}


pachowego. W przypadku podziału dołu pachowego na piętra, 55 (49\%) węzłów chłonnych znajdowało się w obrębie piętra II, 45 (40\%) w zakresie piętra I, a 12 (11\%) w piętrze III.

\section{DYSKUSJA}

Limfoscyntygrafia węzła wartowniczego jest metodą czułą i dokładną w detekcji i określaniu lokalizacji zmian występujących w węzłach chłonnych. W dużej mierze jest to zasługą stosowania coraz bardziej zaawansowanych technologicznie metod obrazowania [7, 9, 11, 12, 13, 14, 15, 16,17]. Wielu autorów wskazuje na zdecydowanie większą czułość technik tomograficznych w porównaniu z klasyczną metodą planarną [11, 12, 13, 14, 15,16]. Wniosek ten pokrywa się z wynikami badań własnych. Ponadto autorzy wskazują na lepszą wykrywalność w badaniach tomograficznych obecnych w badaniach planarnych fałszywie dodatnich gorących miejsc, głównie spowodowanych źle przeprowadzoną iniekcją radioznacznika [11, 12, 15]. Badania tomograficzne pozwalają także na detekcję tzw. ukrytych węzłów chłonnych wartowniczych. Są to węzły, które w związku z pewnymi czynnikami nie zostają wykryte za pomocą klasycznych technik obrazowania stosowanych w limfoscyntygrafii. Tego typu sytuacja może wynikać z czynników zależnych od pacjenta i jego choroby (waga i wiek, rozmiar guza, liczba zajętych węzłów chłonnych, ich lokalizacja), jak też może zależeć od protokołu badania (dobór dawki i rodzaju radioznacznika, sposób jego iniekcji) $[7,11,12,13,14,15$, 16, 17, 18, 19, 20, 21, 22]. Autorzy przytoczonego piśmiennictwa wykazują lepszą wykrywalność metodami tomograficznymi węzłów o trudnej lokalizacji (m.in. w pobliżu miejsca iniekcji, za żebrami). Van der Ploeg i wsp. [16] wskazują na lepszą detekcję ukrytych węzłów chłonnych wartowniczych w obrazach tomograficznych w przypadku ich lokalizacji w dole pachowym, natomiast Lerman i wsp. [12] stwierdzają znaczącą wyższość technik tomograficznych przy wykrywaniu tego typu węzłów u osób otyłych.

Porównanie czułości technik SPECT oraz SPECT/CT względem detekcji węzłów chłonnych wartowniczych nie przyniosło jednoznacznych wniosków. Część autorów wykazuje zdecydowaną wyższość techniki SPECT/CT nad techniką SPECT [12, 13], inni natomiast nie odnotowali różnicy $[11,14,15]$. W materiale własnym także takiej różnicy nie zaobserwowano.

W kwestii spływu limfatycznego jednoznacznie stwierdzono, że najczęstszą lokalizacją jest dół pachowy [11, 12, 13, 14, 15], co pokrywa się z obserwacjami własnymi. Jednakże większość autorów zaobserwowała znaczący (nawet do 30\%) spływ chłonki do śródpiersia [11, 12, 13, 14, 15]. Ponadto w większości prac spływ limfatyczny został określony technikami tomograficznymi oraz metodą planarną, a w badaniu własnym udało się to zrobić jedynie metodą SPECT/CT [11, 12, 13, 14, 15]. Należy jednak podkreślić, że zastosowanie techniki SPECT/CT zmieniło charakter informacji anatomicznej z orientacyjnej i przypuszczalnej na pewną i jednoznaczną.

Określanie lokalizacji węzłów chłonnych wartowniczych dołu pachowego było możliwe, podobnie jak w badaniu własnym, tylko w przypadku techniki SPECT/CT $[11,12,13,16]$. Lerman i wsp. [11,12] wykazali inne rozmieszczenie węzłów chłonnych dołu pachowego względem jego pięter. Należy jednak pamiętać, że podział dołu pachowego na pietra ma charakter umowny i w dużej mierze zależy od subiektywnej oceny lekarza specjalisty. Dodatkowo podczas badania SPECT/CT ręce pacjenta spoczywają za głową, co zaburza anatomiczny układ pięter w dole pachowym. W piśmiennictwie brakuje natomiast informacji na temat określania lokalizacji węzłów chłonnych wartowniczych dołu pachowego w odniesieniu do znajdujących się w nim struktur anatomicznych.

Podsumowując, przeprowadzanie limfoscyntygrafii węzła wartowniczego za pomocą hybrydowego systemu SPECT/CT umożliwia dokładniejszą lokalizację wykrytych zmian, wnosząc przy tym istotną informację dla lekarza chirurga przeprowadzającego operację biopsji węzła wartowniczego, w związku z czym coraz częściej wypiera klasyczną metodę planarną.

\section{WNIOSKI}

W limfoscyntygrafii węzła wartowniczego w raku sutka czułość technik tomograficznych jest znacznie większa od czułości klasycznej metody planarnej. Zastosowanie korekcji pochłaniania w technice SPECT nie wpływa znacząco na czułość metody, natomiast wnosi istotną informację anatomiczną, niemożliwą do określenia w badaniach planarnym oraz SPECT.

\section{PIŚMIENNICTWO}

1. Motomura K, Egawa C, Komoike Y, Kataoka T, Nagumo S, Koyama H, et al. Sentinel node biopsy for breast cancer: technical aspects and controversies. Breast Cancer 2007;14(1):25-30.

2. Krag DN, Anderson SJ, Julian TB, Brown AM, Harlow SP, Ashikaga T, et al. Technical outcomes of sentinel-lymph-node resection and conventional axillary-lymph-node dissection in patients with clinically node-negative breast cancer: results from the NSABP B-32 randomised phase III trial. Lancet Oncol 2007;8(10):881-8.

3. Mansel RE, Fallowfield L, Kissin M, Goyal A, Newcombe RG, Dixon JM, et al. Randomized multicenter trial of sentinel node biopsy versus standard axillary treatment in operable breast cancer: the ALMANAC Trial. J Natl Cancer Inst 2006;98(9):599-609.

4. Veronesi U, Paganelli G, Viale G, Luini A, Zurrida S, Galimberti V, et al. A randomized comparison of sentinel-node biopsy with routine axillary dissection in breast cancer. N Engl J Med 2003;349(6):546-53.

5. Kapteijn BA, Nieweg OE, Petersen JL, Rutgers EJ, Hart AA, van Dongen JA, et al. Identification and biopsy of the sentinel lymph node in breast cancer. Eur J Surg Oncol 1998;24(5):427-30.

6. Almakiewicz R, Birkenfeld B. Medyczna aparatura jądrowa. In: Birkenfeld B, Listewnik M, editors. Medycyna nuklearna. Obrazowanie molekularne. Szczecin: Wydawnictwo Pomorskiego Uniwersytetu Medycznego w Szczecinie; 2011. p. 174-85.

7. van der Ploeg IM, Valdés Olmos RA, Kroon BB, Nieweg OE. The Hybrid SPECT/CT as an additional lymphatic mapping tool in patients with breast cancer. World J Surg 2008;32(9):1930-4.

8. Kowalski J, Birkenfeld B. Metoda rekonstrukcji obrazów trójwymiarowych. In: Birkenfeld B, Listewnik M, editors. Medycyna nuklearna. Obrazowanie molekularne. Szczecin: Wydawnictwo Pomorskiego Uniwersytetu Medycznego w Szczecinie; 2011. p. 199-206.

9. Keidar Z, Israel O, Krausz Y. SPECT/CT in tumor imaging: technical aspects and clinical applications. Semin Nucl Med. 2003;33(3):205-18. 
10. Goyal A, Newcombe RG, Mansel RE, Chetty U, Ell P, Fallowfield L, et al. Role of routine preoperative lymphoscintigraphy in sentinel node biopsy for breast cancer. Eur J Cancer 2005;41(2):238-43.

11. Lerman H, Metser U, Lievshitz G, Sperber F, Shneebaum S, Even-Sapir E. Lymphoscintigraphic sentinel node identification in patients with breast cancer: the role of SPECT-CT. Eur J Nucl Med Mol Imaging 2006;33(3): 329-37.

12. Lerman H, Lievshitz G, Zak O, Metser U, Schneebaum S, Even-Sapir E. Improved sentinel node identification by SPECT/CT in overweight patients with breast cancer. J Nucl Med 2007;48(2):201-6.

13. Husarik DB, Steinert HC. Single-photon emission computed tomography/ computed tomography for sentinel node mapping in breast cancer. Semin Nucl Med 2007;37(1):29-33.

14. van der Ploeg IM, Valdés Olmos RA, Nieweg OE, Rutgers EJ, Kroon BB, Hoefnagel CA. The additional value of SPECT/CT in lymphatic mapping in breast cancer and melanoma. J Nucl Med 2007;48(11): 1756-60.

15. van der Ploeg IM, Nieweg OE, Kroon BB, Rutgers EJ, Baas-Vrancken Peeters MJ, Vogel WV, et al. The yield of SPECT/CT for anatomical lymphatic mapping in patients with breast cancer. Eur J Nucl Med Mol Imaging 2009;36(6):903-9.
16. van der Ploeg IM, Olmos RA, Kroon BB, Rutgers EJ, Nieweg OE. The hidden sentinel node and SPECT/CT in breast cancer patients. Eur J Nucl Med Mol Imaging 2009;36(1):6-11.

17. Coffey JP, Hill JC. Breast sentinel node imaging with low-dose SPECT/CT. Nucl Med Commun 2010;31(2):107-11.

18. Brenot-Rossi I, Houvenaeghel G, Jacquemier J, Bardou VJ, Martino M, Hassan-Sebbag N, et al. Nonvisualization of axillary sentinel node during lymphoscintigraphy: is there a pathologic significance in breast cancer? J Nucl Med 2003;44(8):1232-7.

19. Chakera AH, Friis E, Hesse U, Al-Suliman N, Zerahn B, Hesse B. Factors of importance for scintigraphic non-visualisation of sentinel nodes in breast cancer. Eur J Nucl Med Mol Imaging 2005;32(3):286-93.

20. Tanis PJ, van Sandick JW, Nieweg OE, Valdés Olmos RA, Rutgers EJ, Hoefnagel CA, et al. The hidden sentinel node in breast cancer. Eur J Nucl Med Mol Imaging 2002;29(3):305-11.

21. Rousseau C, Classe JM, Campion L, Curtet C, Dravet F, Pioud R, et al. The impact of nonvisualization of sentinel nodes on lymphoscintigraphy in breast cancer. Ann Surg Oncol 2005;12(7):533-8.

22. Lo YF, Hsueh S, Ma SY, Chen SC, Chen MF. Clinical relevance of nonvisualized sentinel lymph nodes in unselected breast cancer patients during lymphoscintigraphy. Chang Gung Med J 2005;28(6):378-86. 